Provided for non-commercial research and education use. Not for reproduction, distribution or commercial use.

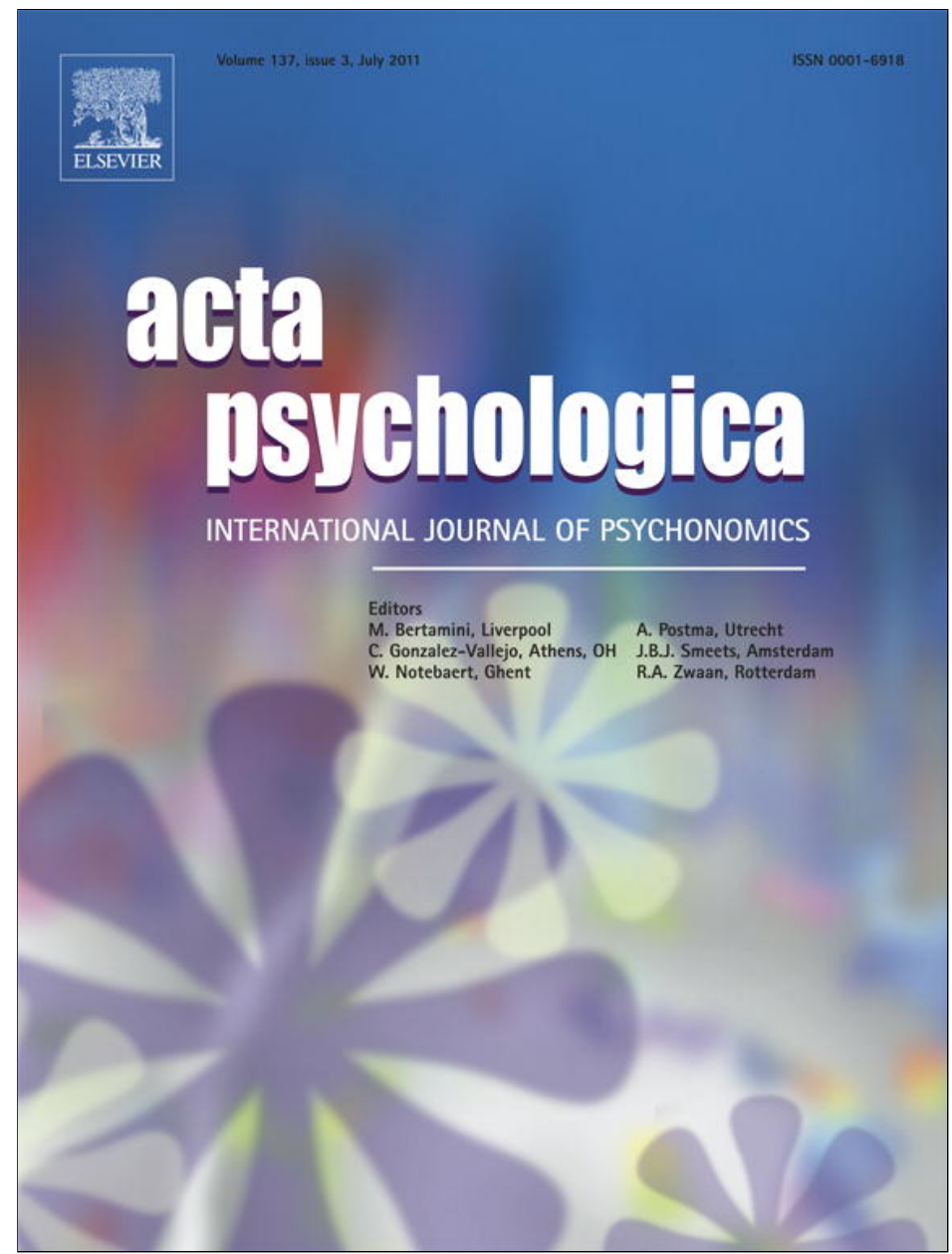

This article appeared in a journal published by Elsevier. The attached copy is furnished to the author for internal non-commercial research and education use, including for instruction at the authors institution and sharing with colleagues.

Other uses, including reproduction and distribution, or selling or licensing copies, or posting to personal, institutional or third party websites are prohibited.

In most cases authors are permitted to post their version of the article (e.g. in Word or Tex form) to their personal website or institutional repository. Authors requiring further information regarding Elsevier's archiving and manuscript policies are encouraged to visit:

http://www.elsevier.com/copyright 


\title{
The effects of interletter spacing in visual-word recognition
}

\author{
Manuel Perea ${ }^{\mathrm{a}, *}$, Carmen Moret-Tatay ${ }^{\mathrm{a}, \mathrm{b}}$, Pablo Gómez ${ }^{\mathrm{c}}$ \\ a Universitat de València, Valencia, Spain \\ b Universidad Católica de Valencia, Valencia, Spain \\ c DePaul University, Chicago, USA
}

\section{A R T I C L E I N F O}

\section{Article history:}

Received 18 May 2010

Received in revised form 7 April 2011

Accepted 8 April 2011

Available online 5 May 2011

\section{PsycINFO classification: \\ 2300 \\ 2340 \\ Keywords: \\ Word processing \\ Letter position coding \\ Letter/word spacing}

\begin{abstract}
A B S T R A C T
Despite the importance of determining the effects of interletter spacing on visual-word recognition, this issue has often been neglected in the literature. The goal of the present study is to shed some light on this topic. The rationale is that a thin increase in interletter spacing, as in casino, may reduce lateral interference among internal letters without destroying a word's integrity and/or allow a more precise encoding of a word's letter positions. Here we examined whether identification times for word stimuli in a lexical decision task were faster when the target word had a slightly wider than default interletter spacing value relative to the default settings (e.g., casino vs. casino). In Experiment 1, we examined whether interletter spacing interacted with word-frequency, whereas in Experiment 2, we examined whether interletter spacing interacted with word length. Results showed that responses to words using a thin increase in interletter spacing were faster than the responses to words using the default settings-regardless of word-frequency and word length. Thus, interletter spacing plays an important role at modulating the identification of visually presented words.
\end{abstract}

(c) 2011 Elsevier B.V. All rights reserved.
In the past decades, a great deal of research in cognitive psychology has been devoted to studying the multiple sublexical/lexical factors that modulate the process of visual-word recognition (e.g., word-frequency, orthographic/phonological similarity, regularity, consistency, length, age of acquisition, etc.; see Andrews, 2006, for review). However, little attention has been paid on the physical features (e.g., typography) that may influence the speed of the recognition of visually presented words (see Moret-Tatay \& Perea in press; Rayner et al. 2010; Slattery \& Rayner 2010). Indeed, the featural-level analysis in the most influential models of visual-word recognition is still based on the uppercase letter font created by Rumelhart and Siple (1974), in which the letters are defined

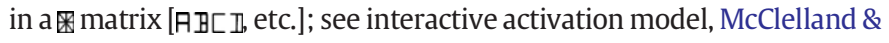
Rumelhart, 1981; multiple read-out model, Grainger \& Jacobs, 1996; dual-route cascaded model, Coltheart, Rastle, Perry, Ziegler, \& Langdon, 2001; spatial coding model, Davis 2010).

Here we focus on the role of a typographic factor such as interletter spacing in the process of visual-word recognition (see Tracy 1987, for a review of fonts and typography). Although current models of visualword recognition do not explicitly deal with interletter spacing, a number of experimental phenomena suggest that this may be a relevant factor during the process of lexical access: variations in interletter spacing may have both beneficial and detrimental effects. On the positive side, an increase in interletter spacing (relative to the default values) may reduce the effects of lateral masking between internal letters of a

* Corresponding author at: Departamento de Metodología, Facultad de Psicología, Av. Blasco Ibáñez, 21, 46010-Valencia, Spain. Fax: + 34963864697.

E-mail address: mperea@valencia.edu (M. Perea). word (i.e., it may decrease the adverse effects of crowding; Bouma 1970, 1973; see also Chung et al. 2001; Chung 2002). For instance, in tasks in which participants have to identify an internal letter, the interference from surrounding letters is reduced by increasing interletter spacing (e.g., Eriksen \& Eriksen 1974). Furthermore, an increase in interletter spacing may also have a beneficial effect in letter position coding. A number of models of visual-word recognition assume that there is some degree of perceptual uncertainty associated with the position of a letter within a word (e.g., overlap model: Gomez et al. 2008; see also spatial coding model: Davis 2010; noisy Bayesian Reader model: Norris, Kinoshita, \& van Casteren, 2010, overlap open-bigram model: Grainger et al. 2006, noisy letter recognition model: Chung \& Legge 2009). This implies that spacing the letters further apart would reduce the position uncertainty parameter in these models, and hence provides a more accurate encoding of letter position. In this light, the ubiquitous presence of transposed-letter effects in visual-word recognition (e.g., the transposed-letter nonword jugde is easily confusable with judge; see O'Connor \& Forster 1981; Perea et al. 2005; Whitney 2001) may be taken as a signal that the word-processing system has difficulty at encoding a word's letter positions using the default interletter spacing.

On the negative side, an increase in interletter spacing beyond some limits may be deleterious for the process of visual-word recognition (see Chung 2002; McLeish, 2007; Paterson \& Jordan 2010; Perea \& Rosa 2002): i) it may destroy the physical integrity of words (i.e., the words will cease to be identified as objects; e.g., as in the word literature), ii) it may affect word-form information which may be relevant in the process of lexical access (e.g., information on word-shape information, such as ascenders/descenders in the letters; see Perea \& Rosa 2002; Yu, Park, 
Gerold, \& Legge, 2010), iii) it may reduce the number of letters that can be recognized at a glance, in particular for long words (see Chung 2002), and iv) it may increase the distance of the letters from the center of the fovea so that retinal acuity will be reduced (see Paterson \& Jordan 2010). As Chung (2002) indicated, "if fewer letters are contained in the visual span due to increased letter spacing, then reading slows down" (p. 1275).

Therefore, on theoretical grounds, increasing the interletter spacing relative to the default interletter spacing may have a positive effect in the process of visual-word recognition (i.e., less crowding and/or more accurate letter position coding); nonetheless, large increases in interletter spacing may have a deleterious effect on lexical access. In addition to the implications to models of orthographic processing, there are practical and instructional implications. As Chung (2002) indicated, "reading speed should improve with letter spacing, up to the critical spacing, at which reading speed reaches its maximum" (p. 1271). Indeed, in his classical text on the Psychology and Pedagogy of Reading, Huey (1908/1968) reviewed very early research on the desirable parameter settings for interletter spacing (e.g., a minimum of $.5 \mathrm{~mm}$ ) and concluded that "any very unusual separation of the letters should be avoided" (p. 408).

The empirical evidence concerning the effects of interletter spacing in visual-word recognition is scarce and sometimes contradictory. In a rapid serial visual presentation, Latham and Whitaker (1996) found faster reading times when words were presented with a slightly wider interletter spacing -the edge-to-edge interletter spacing equaled 1letter width- than with a standard interletter spacing. However, Latham and Whitaker employed very short words (3-letter words) and only four participants, which makes it difficult to generalize their findings. McLeish (2007) also reported that increasing interletter spacing (an increase of $10 \%$ relative to the default spacing) increased reading speed in a continuous reading task relative to the default interletter spacing. Nonetheless, McLeish obtained these findings in a sample of young readers (10-15 years old) with impaired vision (see also Prince 1959, for a similar finding with low-vision readers). Thus, the generalization to a normal-reading population is not obvious. More relevant for our purposes is an unpublished study of Tai et al. (2009). They employed a parametric manipulation of interletter spacing (from narrower to wider spacing) in a continuous reading task in which the participants' eye movements were monitored. Tai et al. found shorter fixation times for those texts presented with a slightly wider interletter spacing (e.g.,The quick brown fox) relative to the default interletter spacing (e.g., The quick brown fox). More specifically, they reported that the average fixation duration of words in sentences was around 253 and $250 \mathrm{~ms}$ for the words presented with $\mathrm{a}+1.0$ and +1.5 interletter spacing (e.g., brown and brown), respectively, whereas the average fixation duration for words presented with the default condition was around $269 \mathrm{~ms}$ (e.g., brown). Tai et al. employed the interletter spacing parameters in the same way as in MS-Word; the term " +1.0 " refers to an expanded 1.0 inter-character spacing in this application. (In passing, the fact that one the most popular word-processing package [MS-Word] allows the user to modify the interletter spacing in words can be used as an indication that interletter spacing plays a relevant role during the processing of visually presented words.)

However, other studies reported no effect of slight increases in interletter spacing in visual-word recognition. Chung (2002), using a rapid serial visual presentation task in which reading speed was taken as the speed that corresponded to $80 \%$ reading accuracy, found that reading speed in peripheral vision with a slightly wider interletter spacing (1.4 times the default spacing) was the same as the reading speed with the default spacing (e.g., $\mathrm{C} \circ \mathrm{m} \mathrm{m} \circ \mathrm{n}$ vs. Common) - while (unsurprisingly) it decreased slightly with large interletter spacings (2 times the default interletter spacing; as in $\mathrm{C} \circ \mathrm{m} \mathrm{m} \bigcirc \mathrm{n}$; see also Yu et al. 2007, for a similar finding). However, we must keep in mind that Chung focused on peripheral rather than on foveal vision, so that these data may not generalize to foveal presentations. In addition, Cohen et al. (2008) manipulated "the number of blank spaces between letters
$(0,0.75,1.5,2.25$, or 3 spaces)" (p. 355) in a semantic categorization task ("is it an animal?"). They failed to find a significant difference in response times when the words were presented with the slightly wider interletter spacing than when the words were presented with the default interletter spacing (e.g., mouton) and when the word had a 0.75 and 1.15 blank spaces between letters (e.g., $\mathbf{m} \boldsymbol{\circ} \mathbf{u} \mathbf{t} \boldsymbol{\circ} \mathbf{n}$ and $\mathbf{m} \boldsymbol{\circ} \mathbf{u} \boldsymbol{t} \mathbf{0} \mathbf{n}$ respectively). Unsurprisingly, response times were longer when the number of blank spaces was 2.25 or 3 (e.g., $\mathbf{m} \bullet \mathbf{u} \boldsymbol{t} \bullet \mathbf{n}$ and $\mathbf{m} \quad \mathbf{0} \quad \mathbf{u} \quad \boldsymbol{t} \quad \mathbf{0} \quad \mathbf{n})$. Cohen et al. (2008) indicated that "letters separated by more than 2 spaces cannot send converging activation to common bigram detectors, thus disrupting the parallel encoding of letter strings" (p. 361; see also Van Overschelde \& Healy 2005 , for a similar reasoning).

Finally, a recent eyetracking experiment by Paterson and Jordan (2010) examined the role of interletter spacing (default vs. wide [one extra character] interletter spacing; e.g., "cuisine" vs. "c u i s i n e") for low- and high-frequency words embedded in sentences. For the sentences with increased interletter spacing, Paterson and Jordan employed a single interword spacing (e.g., " $t \mathrm{~h}$ e great c u i s i n e"), a double interword spacing (e.g., " $\mathrm{t} h$ e gre a $\mathrm{t}$ c u i s i $\mathrm{n}$ "), or a triple interword spacing (e.g., "t he gre a t c u i s i n e"). There was an important reading cost when there were no cues delimiting the word boundaries as was the case in the increased letter spacing/single word spacing condition (see Perea \& Acha, 2009; Rayner, Fischer, \& Pollatsek, 1998, for similar findings with unspaced text). Importantly, even though the manipulation of interletter spacing was (very likely) above the optimal value, the first-fixation durations on the target word were remarkably similar for the standard letter spacing/single word spacing condition (241 ms) and for the two increased letter spacing conditions (triple word spacing: $242 \mathrm{~ms}$; double word spacing: $245 \mathrm{~ms}$ ). Furthermore, although gaze durations (i.e., the time spent on the target word before leaving it) were shorter in the standard letter spacing/single word spacing condition $(284 \mathrm{~ms})$ than in the increased letter spacing conditions (triple word spacing: $347 \mathrm{~ms}$; double word spacing: $392 \mathrm{~ms}$ ), this finding was qualified by the greater percentage of firstpass regressions from the target word in the standard letter spacing/ single word spacing condition (22.5\%) than in the other two conditions (13\% in both cases). Thus, even in a scenario in which the distance among the letters was rather wide (i.e., compare cuisine vs. $c u$ i $s$ i $n e$ ), the deleterious effect of increasing interletter spacing was relatively mild ${ }^{1}$.

Taken together, the findings from the previously cited studies, using quite different populations and methodologies, offer some hints but they do not allow making firm conclusions on the role of thin increases of interletter spacing in visual-word recognition. The Tai et al. (2009) experiment is probably the clearest evidence in favor of a beneficial effect of increasing interletter spacing on lexical access. However, only global reading measures were obtained - and this is an unpublished study. We believe that it is important to revisit this issue by focusing on local measures rather than on global reading measures; this way, we can examine whether the effect of interletter spacing is affected by lexical and sublexical factors. Here we employ an online word identification task, the lexical decision task, which is quite sensitive to small effects (see Ratcliff et al. 2004, for a model of this task). As Rayner (1998) indicated, "researchers can have some confidence that results obtained with

\footnotetext{
${ }^{1}$ For gaze durations, Paterson and Jordan (2010) reported a significant interaction between interletter spacing and word-frequency: low-frequency words were more hindered by increases of interletter spacing than high-frequency words. This was interpreted as an indication that interletter spacing affected the stage of visual identification - using Sternberg's additive-factor logic. However, this interaction was essentially due to the inclusion of the Increased interletter spacing/single interword spacing in the analyses (i.e., a condition in which the WORD boundaries are not delimited e.g., " $t \mathrm{~h}$ e $g r$ e $\mathrm{t}$ c u i $s$ i $n$ e"; see Table 2 in Paterson \& Jordan, 2010); indeed, the Interletter spacing $\times$ Word-frequency interaction is not close to significance when this condition is excluded.
} 
standard naming and lexical decision tasks generalize to word recognition processes while reading" (p. 392) (e.g., see Acha \& Perea 2008b; Davis et al. 2009; Johnson, Perea, \& Rayner, 2007; Perea \& Pollatsek 1998, for a few instances). Furthermore, single-word identification tasks provide ecologically valid information (e.g., when we process sign roads, the name of bus/subway stations, names of products/stores, etc). (We discuss the generalization of the present findings to a "normal silent reading" situation in the General Discussion.)

In summary, we examined whether identification times for words in a lexical decision task were affected by interletter spacing. On theoretical grounds, a thin increase in interletter spacing may reduce lateral interference among letters and/or allow a more precise encoding of a word's letter position without destroying critical whole-word information. (Note that the crowding account and the location uncertainty account and are not mutually exclusive, and the present experiments were not designed to distinguish between these two proposals) In the present experiments, we employed two interletter spacing conditions: i) words were presented with default interletter spacing, and ii) words were presented with a thin increase in interletter spacing ( $+1.2 \mathrm{pt}$; i.e., compare ca sin o vs. casino) - note that this value is similar to that employed by Tai et al. (2009).

The study of the effects of the interletter spacing has another implication for models of visual-word recognition. Many models make a distinction between what is termed lexical vs. sub-lexical components. Rumelhart and Siple (1974), for example, assumed that there is a combination of the sensory information (sub-lexical) and the internal representations about language (lexical) in the process of visual-word recognition. More recently, Ratcliff et al. (2004) accounted for lexical decision task data with a model with separate encoding time parameter (sub-lexical: $\mathrm{T}_{\mathrm{er}}$ ), and decisional information (lexical: drift rate). To test whether the effect of interletter spacing affects lexical and/or sublexical factors, we examined whether interletter spacing interacted with wordfrequency (i.e., a lexical effect; Experiment 1 ) and with word length (i.e., a sublexical effect; Experiment 2). The underlying idea of behind the manipulation of word-frequency is the following: if we assume a discrete stage model of performance in which the subprocesses are identified as successive temporal stages, then manipulations that affect different processing stages would produce additive effects, whereas manipulations that affect the same processing stage would produce an interaction (Sternberg 1969; see also Posner 2005, for a recent review of the additive-factor logic). Word-frequency is a lexical factor which affects the word-identification stage. Thus, if the effect of interletter spacing occurs at a very early encoding level (e.g., if increases in interletter spacing may produce an advantage at encoding letter positions and/or at encoding letter identities) rather than at a wordidentification stage, its effect should be similar in magnitude for lowand high-frequency words. Alternatively, if a small increase of interletter spacing affects the stage of word identification, the two factors should interact. In Experiment 1, we used short five-letter words so that words with an increased interletter spacing could be readily perceived in glance (e.g., compare canal with canal).

In Experiment 2, we employed 5- vs. 8- letter words. The rationale of the manipulation of a sublexical factor such as word-length is slightly different from that of word-frequency because, unlike word-frequency, word-length does not have an appreciable effect on word recognition with adult skilled readers (at least in the range of 5-8 letters; e.g., see Acha \& Perea 2008a). The logic here is that an increase in interletter spacing in long stimuli (e.g., compare festival with festival) may lead to a decline in the number of letters that can be recognized at a glance, in particular (i.e., the visual span; see Chung 2002) and/or to a decline in the retinal acuity (i.e., letters may more difficult to perceive the further they are from the fixation point; see New et al., 2007). Therefore, a wider interletter spacing effect may lead to a benefit for short five-letter words, but it may have a null (or even detrimental) effect for the longer words.

The stimuli in the present experiments were presented in a highly popular font: Times New Roman. This font has been used as a default in multiple computer applications and written newspapers - note that it is the recommended choice by the American Psychological Association when submitting manuscripts for publication. Finally, given that the effects of thin increases of interletter spacing may be small in magnitude, we included a large number of words per spacing condition (80 in Experiment 1 and 160 in Experiment 2).

\section{Experiment 1 (word-frequency and interletter spacing)}

\subsection{Method}

\subsubsection{Participants}

Thirty-eight students from the University of Valencia participated voluntarily in the experiment. All of them either had normal or corrected-to-normal vision and were native speakers of Spanish. None of them reported having any reading disability.

\subsubsection{Materials}

We selected a set of 160 words of five letters from the Spanish database (Davis \& Perea 2005). Eighty of these words were of lowfrequency (mean: 3.1 per million, range: 0.36-6.96) and the other eighty words were of high-frequency (mean: 48.2 per million, range: 10.0-383.6). Factors like bigram frequency, N, and syllable frequency of the initial syllable were controlled (mean log bigram frequency: 2.70 in the two groups; Coltheart's N: 4.3 and 4.2 for low- and high-frequency words respectively; mean syllable frequency: 861 and 866 per million, for low- and high-frequency words). For the purposes of the lexical decision task, 120 pronounceable nonwords of five letters were created by changing two/three letters from Spanish words other than the ones in the experimental set. The mean log bigram frequency (mean: 2.7 ) and $\mathrm{N}$ (mean: 3.9) were similar as those for word stimuli. Word and nonword stimuli were counterbalanced across two experimental lists so that if a letter-string was presented in the default interletter spacing in the first list, it would be presented in a slightly wider interletter spacing in the second list. Stimuli were presented in 14-pt Times New Roman either with the default spacing or with a +1.2 interletter spacing (e.g., compare canal with canal) in MS-Word.

\subsubsection{Procedure}

Participants were tested individually in a quiet room. Presentation of the stimuli and recording of response times were controlled by DMDX (Forster \& Forster 2003). On each trial, a fixation point (“+”) was presented at the center of the screen for $500 \mathrm{~ms}$. Then, the target stimulus was presented in lowercase and remained on the screen until the participant's response - or until 2500 ms had elapsed. Participants were instructed to press one of two buttons on the keyboard to indicate whether the letter string was a Spanish word or not. This decision was to be made as rapidly and as accurately as possible. Reaction times were measured from the onset of the letter string until the participant's response. Each participant received a different random order of stimuli. Each participant received a total of 24 practice trials prior to the experimental phase. The session lasted approximately $18 \mathrm{~min}$.

\subsection{Results and discussion}

Incorrect responses and reaction times less than $250 \mathrm{~ms}$ or greater than $1500 \mathrm{~ms}$ (less than $0.5 \%$ ) were excluded from the latency analysis. The mean latencies for correct responses and error rates are presented in Table 1. For word stimuli, ANOVAs based on the participant and item response latencies and error percentage were conducted based on a 2 (word-frequency: low, high) $\times 2$ (spacing: default, slightly wider) $\times 2$ (list: list 1 , list 2 ) design. For nonword stimuli, ANOVAs based on the participant and item response latencies and error percentage were conducted based on a 2 (spacing: default, slightly wider $) \times 2$ (list: list 1 , list 2 ) design. List was included as a 
Table 1

Mean lexical decision times (in ms) and percentage of errors (in parentheses) for words and pseudowords in Experiment 1.

\begin{tabular}{lll}
\hline & Low-frequency & High-frequency \\
\hline Normal spacing & $642(9.9)$ & $577(2.2)$ \\
Wide spacing & $620(10.5)$ & $562(1.6)$ \\
\hline
\end{tabular}

Note: The mean RT and error percent for pseudowords were $695 \mathrm{~ms} \mathrm{(7.0 \% )} \mathrm{and} 700 \mathrm{~ms}$ (8.3\%) for the default and slightly wider interletter spacing conditions, respectively.

dummy factor to remove the variance associated with the counterbalancing lists (Pollatsek \& Well 1995).

\subsubsection{Word targets}

The ANOVA on the latency data showed that high-frequency words were responded to more rapidly than low-frequency words, F1 $(1,36)=$ 73.67, $\mathrm{MSE}=1926.5, \mathrm{p}<.001 ; \mathrm{F} 2(1,156)=74.99, \mathrm{MSE}=4954.6$, $\mathrm{p}<.001$. More importantly, words with a slightly wider interletter spacing were responded to faster than words with the default interletter spacing, $\mathrm{F} 1(1,36)=4.20, \mathrm{MSE}=2723.1, \mathrm{p}<.05 ; \mathrm{F} 2(1,156)=23.04$, $\mathrm{MSE}=1454.6, \mathrm{p}<.001$. The interaction between the two factors did not approach significance (both ps $>20$ ).

The ANOVA on the error data only showed that participants committed more errors to low-frequency words than to high-frequency words, $\mathrm{F} 1(1,36)=80.80, \mathrm{MSE}=33.6, \mathrm{p}<.001, \mathrm{~F} 2(1,156)=32.25$, $\mathrm{MSE}=149.47, \mathrm{p}<.001$. The other effects were not significant (all Fs $<1$ ).

\subsubsection{Nonword targets}

The ANOVA on the latency data failed to show an effect of interletter spacing (both $\mathrm{Fs}<1$ ). The ANOVA on the error data only showed that participants committed $1.3 \%$ more errors to nonwords presented with a slightly wider interletter spacing than to nonwords with the default interletter spacing, $\mathrm{F} 1(1,36)=6.61$, $\mathrm{MSE}=4.69$, $\mathrm{p}<.02, \mathrm{~F} 2(1,155)=3.37, \mathrm{MSE}=32.27, \mathrm{p}=.068$.

The results of the present experiment are clear. First, leaving aside the ubiquitous word-frequency effect, we found faster response times (around $18 \mathrm{~ms}$ ) for the words presented with a slightly wider interletter spacing (e.g., canal) than for the words presented in the default interletter spacing (canal). That is, interletter spacing seems to be a relevant factor to take into account in visual-word recognition experiments. Second, the magnitude of the effect of spacing was similar for low- and for high-frequency words ( $22 \mathrm{vs.} 15 \mathrm{~ms}$ ). ${ }^{2}$ Third, the effect of interletter spacing was absent for pseudowords in the latency analysis, while there was a very small (1.3\%) detrimental effect in the error data.

The questions now are: i) whether the effect of interletter spacing obtained in Experiment 1 can be replicated with a different sample of items, and ii) whether the effect of interletter spacing is modulated by word-length. To that end, we selected a set of 160 five-letter words (e.g., canal vs. canal) and 160 eight-letter words (e.g., festival vs. festival). The issue here is whether, for the eight-letter words, the positive effects of an increase in interletter spacing (e.g., less lateral inhibition and/or more accurate letter position coding) may be cancelled out by the potentially detrimental effects of interletter spacing (i.e., the fixation point will be slightly farther away from the letters). It is important to

\footnotetext{
${ }^{2}$ Even though the interaction between interletter spacing and word-frequency did not approach significance, the magnitude of the effect of interletter spacing was numerically smaller for high-frequency words $(15 \mathrm{~ms})$ than for low-frequency words (22 ms). Nonetheless, note that there was a small $(-0.6 \%)$, nonsignificant detrimental effect for the low-frequency words -post hoc analyses failed to find any signs of a speed-accuracy trade-off in this condition though. In addition, to re-examine whether the effect of interletter spacing could be reduced for high-frequency words, we conducted an additional lexical decision experiment with a new set of short (4- and 6letter long) high-frequency words (mean word frequency: 58 per million). We found a significant 33-ms advantage for the words presented in the slightly wider interletter spacing condition than in the default interletter spacing condition. Thus, the effect of interletter spacing is a reliable finding for high frequency words.
}

note here that, for skilled readers, the number of letters in lexical decision experiments has a detrimental effect in the recognition of nonwords, but not of words (e.g., see Acha \& Perea 2008a).

\section{Experiment 2 (word-length and spacing)}

\subsection{Method}

\subsubsection{Participants}

Sixteen students from the University of Valencia participated voluntarily in the experiment. All of them either had normal or corrected-to-normal vision and were native speakers of Spanish. None of them reported having any reading disability.

\subsubsection{Materials}

We selected a set of 320 words from the Spanish database (Davis \& Perea 2005). One-hundred and sixty of these words were of five letters and the other One-hundred and sixty words were of eight letters. Factors like word-frequency (mean word-frequency per million: 37.6 and 36.3 for the 5-letter and 8-letter words, respectively) and $\mathrm{N}$ (mean 0.55 and 0.41 for the 5-letter and 8-letter words, respectively) were controlled. For the purposes of the lexical decision task, 320 nonword targets were created (160 of five letters and 160 of eight letters). The mean number of neighbors (Coltheart's N: 0.34) was similar to that for words. Word and nonword stimuli were counterbalanced across two experimental sets of materials so that if a letter-string was presented in the default interletter spacing in the first set, it would be presented in a slightly wider interletter spacing in the second set.

\subsubsection{Procedure}

It was the same as in Experiment 1. That is, stimuli were presented in 14-pt Times New Roman, and the condition with a slightly wider interletter spacing had a +1.2 interletter spacing (e.g., hotel vs. hotel; festival vs. festival).

\subsection{Results and discussion}

Incorrect responses and reaction times less than $250 \mathrm{~ms}$ or greater than $1500 \mathrm{~ms}$ (less than 1\%) were excluded from the latency analysis. The mean latencies for correct responses and error rates are presented in Table 2. For word and nonword targets, ANOVAs based on the participant and item response latencies and error percentage were conducted with a 2 (length: 5 letters, 8 letters) $\times 2$ (spacing: default, slightly wider) $\times 2$ (list: list 1 , list 2 ) design.

\subsubsection{Word targets}

The ANOVA on the latency data showed words with a slightly wider interletter spacing were responded to $36 \mathrm{~ms}$ faster than the words with the default interletter spacing, thus replicating the findings from Experiment 1, F1 $(1,14)=11.06, \mathrm{MSE}=1853.1, \mathrm{p}<.005 ; \mathrm{F} 2(1,316)=$ 93.38, $\mathrm{MSE}=2250.4, \mathrm{p}<.001$. Neither the effect of length nor the interaction between the two factors approached significance (all Fs $<1$ ).

The ANOVA on the error data only showed that participants committed more errors to words with standard interletter spacing than

Table 2

Mean lexical decision times (in ms) and percentage of errors (in parentheses) for words and pseudowords in Experiment 2.

\begin{tabular}{lll}
\hline & 5-letter stimuli & 8-letter stimuli \\
\hline Words & $599(5.5)$ & \\
$\begin{array}{l}\text { Normal spacing } \\
\text { Wide spacing }\end{array}$ & $561(4.5)$ & $604(5.3)$ \\
& & \\
$\begin{array}{l}\text { Pseudowords } \\
\text { Normal spacing }\end{array}$ & $603(3.6)$ & $659(3.2)$ \\
Wide spacing & $602(3.7)$ & $680(4.2)$ \\
\hline
\end{tabular}


to words with a slightly wider interletter spacing, although the effect did not reach significance in the analysis by subjects, $F 1(1,14)=3.43$, $\mathrm{MSE}=8.73, \mathrm{p}=.085 ; \mathrm{F} 2(1,316)=5.56, \mathrm{MSE}=53.83, \mathrm{p}<.02$.

\subsubsection{Nonword targets}

The ANOVA on the latency showed that responses to eight-letter nonwords took longer than the responses to five-letter nonwords, F1 $(1,14)=12.57, \quad \mathrm{MSE}=5667.4, \mathrm{p}<.001 ; \mathrm{F} 2(1,316)=105.34$, MSE $=6444.0, \mathrm{p}<.001$, and that response times to nonwords with a wide interletter spacing were longer to the responses to nonwords with the default interletter spacing, $\mathrm{F} 1(1,14)=5.92$, MSE $=256.4$, $\mathrm{p}<.03 ; \mathrm{F} 2(1,316)=6.36, \mathrm{MSE}=3508.3, \mathrm{p}<.015$. The interaction between the two factors was significant, $F 1(1,14)=13.82$, $\mathrm{MSE}=151.5, \mathrm{p}<.003 ; \mathrm{F} 2(1,316)=5.60, \mathrm{MSE}=3508.3, \mathrm{p}<.02$ : the detrimental effect of interletter spacing occurred for 8-letter nonwords, $\mathrm{F} 1(1,14)=13.21, \mathrm{MSE}=271.6, \mathrm{p}<.003 ; \mathrm{F} 2(1,158)=10.45$, $\mathrm{MSE}=4010.4, \mathrm{p}<.002$, but not for 5 -letter nonwords (both Fs $<1$ ).

The ANOVA on the error data did not reveal any significant effects (all Fs $<1$ ).

The results of the present experiment replicated the main finding of Experiment 1: lexical decision times for words were faster when there was a slight increase in interletter spacing -relative to the default setting. Furthermore, this effect occurred to a similar degree for short and for long words. As usual, there were no signs of an effect of length for the word stimuli (e.g., Acha \& Perea 2008a).

For nonwords, we found a detrimental effect of number of letters: the recognition of longer nonwords took longer than the recognition of shorter nonwords (e.g., see Acha \& Perea 2008a, for a similar finding). Furthermore, for short nonwords, we did not find an effect of interletter spacing in the latency data -thus replicating the findings of Experiment 1. But one remarkable finding here is that we found a detrimental effect of interletter spacing for the long nonwords. (We discuss this finding in the General Discussion.)

\section{General discussion}

We conducted two lexical decision experiments that examined the role of interletter spacing in visual-word recognition. The main findings can be summarized as follows. First, identification times were shorter for words presented with a slightly wider interletter spacing than for the words presented with the default interletter spacing (i.e., canal being recognized faster than canal). Second, for word stimuli, the effect of interletter spacing was independent of word-frequency (Experiment 1) and word length (Experiment 2). Third, for nonword stimuli, we found a detrimental effect of interletter spacing in the latency data for the longer, but not for shorter items. Fourth, although the effects of spacing on response times are remarkably consistent, they were absent in the accuracy data, although in Experiment 1, for nonword targets, there was a small (1.3\%) detrimental effect. As we discuss below, these findings have important implications from a theoretical point of view and from an applied perspective.

The present data are consistent with the results reported by Latham and Whitaker (1996), McLeish (2007), and Tai et al. (2009), who also found some facilitative effects of a slight increase of interletter spacing in other paradigms and populations - relative to the default spacing. At first glance, the present findings may seem at odds with the null effect of interletter spacing on response times reported by Cohen et al. (2008). However, the interletter spacings employed by Cohen et al. were probably wider than the "optimal" interletter value. Note that even the "slightly wider" interletter spacing condition employed by Cohen et al. (2008); e.g., m $\mathbf{0} \mathbf{u} \boldsymbol{t} \mathbf{0} \mathbf{n}$ ) was substantially larger than those used by Tai et al. (2009); e.g., brown) or in the present experiments (e.g., canal). In fairness to Cohen et al., the aim of their study was to produce "stimulus degradation by letter spacing" rather than examining potential benefits of interletter spacing on lexical access.
As indicated in the Introduction, a factor such as interletter spacing may have both a positive and a deleterious effect in the processing of visually presented words. On the positive side, increases in interletter spacing, as in canal, produce a reduction in lateral inhibition (i.e., less crowding effects; see Chung 2002) relative to the default spacing, and they may also allow a more precise stage of letter position coding (i.e., less perceptual uncertainty, Davis 2010; Gomez et al. 2008). (Disentangling the potential role of these non-exclusive accounts would go beyond the scope of the present study.) On the negative side, an increase of interletter spacing beyond a certain limit may not only hinder a word's physical integrity, but also the distance of the letters from the center of the fovea so that retinal acuity is reduced. In the present experiments, the manipulation was quite subtle for word stimuli (e.g., compare canal vs. canal) so that the potential benefits (less crowding and/or less perceptual uncertainty may lead to advantage at encoding letter identities and/or at encoding letter positions) overcame the potential disadvantages of increasing interletter spacing.

One important aspect of the present experiments is that we examined whether the effect of interletter spacing was modulated by lexical and sublexical factors. Using Sternberg (1969) additive factor logic (see also Posner, 2005), if the facilitative effect of interletter spacing occurs at an early perceptual stage, its impact should not be modulated by a lexical factor such as word-frequency. This is actually what occurred in Experiment 1: the effect of interletter spacing was similar for high- and low-frequency words. A more complex issue is the relationship between interletter spacing and a sublexical effect such as word length, which was examined in Experiment 2. As usual, the effect of length was absent for word stimuli (see Acha \& Perea 2008a). This implies that word units of different lengths are tuned to settle at approximately the same time in adult skilled readers. Under these conditions, the effect of interletter spacing was similar in size for short words and for long words. Thus, despite the fact that the word processing system is forced to work across a wider spatial area, in particular for long words (e.g., compare festival vs. festival), there is a similar benefit from a thin increase of interletter spacing - relative to the default settings. For pseudowords, we found the usual length effect (i.e., slower responses for long than for short pseudowords; see Acha \& Perea 2008a, for a similar finding). Importantly, this length effect was accompanied by a detrimental effect of interletter spacing which was restricted for long pseudowords (a 21-ms effect). As an anonymous reviewer suggested, this latter finding is consistent with the view that response times to pseudowords may depend on how long it takes for all phonemes to settle individually. More letters imply that more phonemes must settle independently; therefore serial processing in the phonological route implies longer reaction times for pseudowords, as actually occurs. Presumably, the disadvantages due to this serial process across a slightly wide spatial area were more than the advantages of the increase of interletter spacing. In contrast, for shorter nonwords, these two opposite processes may have counteracted, resulting in no overall benefit/cost of increased interletter spacing - as actually occurred in Experiments 1-2.

In short, we believe that the lack of a word-frequency by spacing interaction reflects that the inter-letter spacing effect occurs at an early, pre-lexical level. On the other hand, the lack of interaction with word length for words once again shows that letter length (at least within the range of 5-8 letters) is not a factor that affects word identification. Importantly, even if the locus of interletter spacing is at an early processing stage, the advantage of a thin increase in interletter spacing may be useful for further processing. Within the context of the diffusion model of the lexical decision task (Ratcliff et al. 2004), there is a distinction between the encoding processes (the $\mathrm{T}_{\mathrm{er}}$ parameter in the model) and the quality of the information driving the decisional process (the drift rate parameter). Importantly, changes in encoding time produce shifts in the RT distributions, while changes in the quality of the perceptual information produce larger effects in the tail than in the leading-edge of the RT 
distributions (e.g., see Gomez, Ratcliff, \& Perea, 2007). An analysis of the RT distributions word stimuli from Experiments 1-2 (averaging across conditions) suggest that the beneficial effect of interletter spacing on word processing is in the quality of the perceptual information. This is so because the effect of interletter spacing for word stimuli is $2,8,18,26$, and $34 \mathrm{~ms}$ for the $.1, .3, .5, .7, .9$ quantiles, respectively, in Experiment 1, and 17, 23, 34, 42, and $56 \mathrm{~ms}$ for the 1 , $.3, .5, .7, .9$ quantiles, respectively, in Experiment 2. That is, the effect of interletter spacing on word stimuli grows as a function of the quantiles. This suggests that the effect of interletter spacing is not merely an encoding phenomenon: its impact carries over further down the word-processing stream. ${ }^{3}$ What about the deleterious effect of interletter spacing on long nonwords found in Experiment 2? The effect of interletter spacing was $-20,-25,-12,-33$, and $-25 \mathrm{~ms}$ for the $1, .3, .5, .7, .9$ quantiles. That is, the effect of interletter spacing for long nonwords was approximately the same at each quantile: it involved a shift in the entire RT distribution. (Not surprisingly, there were no signs of an effect of interletter spacing for the short pseudowords: the effect of interletter spacing in Experiment 2 was $-3,-2,-1,-4$, and $-2 \mathrm{~ms}$ for the $.1, .3, .5, .7, .9$ quantiles, respectively.) Taken together, the RT distributional analyses suggests that the beneficial effect of interletter position encoding on word processing affects the quality of information (drift rate in a diffusion model), while the detrimental effect of interletter position coding on (long) nonwords seems to be due to encoding processes $\left(\mathrm{T}_{\mathrm{er}}\right.$ in a diffusion model).

The implications of the present experiments are not just theoretical. In the new digital era, computer software companies have a particular interest in creating optimal readable/legible fonts and text parameters that may produce faster reading times when reading on a computer screen (see Larson 2006). The presence of faster identification times to word stimuli when presented with a slightly wider interletter spacing than when presented using default interletter value strongly suggests that the "default" interletter settings may not be the optimal one. We must bear in mind that the "default" interletter spacing has been set by the publishing companies with no previous (published) empirical work on its impact on reading speed (see McLeish 2007): it would be a quite a fortunate coincidence if the "default" interletter spacing value were the optimal. Determining the optimal values for the interletter spacing is a goal of researchers investigating visual-word recognition and reading (see Rayner et al. 2010). We acknowledge that more research is needed to examine in greater detail the optimal interletter value using a large set of interletter spacing conditions. This would require a large set of items/condition to obtain enough experimental power given that the small variations in interletter spacing may produce tiny effects -note that these optimal values may also depend on other text parameters such as print size and, furthermore, individual differences cannot be excluded $^{4}$

The present study has demonstrated that interletter spacing plays an important role in the recognition of visually presented words. The identification of single words provides ecologically valid informationi.e., when we process sign roads, the name of bus/subway stations,

\footnotetext{
${ }^{3}$ Within the diffusion model framework, at high accuracy levels, small changes in the quality of the perceptual information produce changes in the RT distribution, and negligible changes in accuracy. This is consistent with the robust significant effects in $\mathrm{RT}$, and the null effects in accuracy.

${ }^{4}$ In a previous study, McLeish (2007) noted that there was a large amount of individual differences when manipulating interletter spacing. In a post hoc analysis, McLeish indicated that "readers with slow reading speeds have the most to gain from the benefits of increased letter spacing" (p. 141). Indeed, the apparent divergence across the effect of interletter spacing for word stimuli in Experiments 1 and 2 (18 and $36 \mathrm{~ms}$, respectively) suggests that individual differences may modulate the effects of interletter spacing. (Note that the replication of Experiment 1, with a new set of items, showed a 33-ms effect). Thus, one relevant issue for further research is to manipulate interletter spacing in samples of lower-reading individuals and higher-reading individuals.
}

names of products/stores, etc. Nonetheless, we believe that it is important to examine whether the effects of interletter spacing also apply to normal silent reading. The point here is that in a normal reading situation, the advantages of a slight increase in the interletter spacing (i.e., a reduction in lateral interference and/or a more accurate letter position coding) may be cancelled out by the decrease in acuity when the words with a wider interletter spacing were processed in the parafovea (i.e., a component which is absent in a single-word identification task). In an unpublished study using global reading measures, Tai et al. (2009) found faster fixation times and longer saccades when the interletter spacing in the text was slightly wider than the default spacing - consistent with the data presented here. However, the overall reading speed in the Tai et al. experiment was not affected by a small increase of interletter spacing. In addition, Paterson and Jordan (2010) found a detrimental effect of interletter spacing on the total reading times. Nonetheless, as indicated in the Introduction, the interletter spacing employed in the Paterson and Jordan experiment was rather large (one extra space between letters; e.g., as in " $t h e g r e a t c u$ i $s i n e$ "), and, as Paterson and Jordan acknowledged, this manipulation could have disrupted the visual integrity of the words. Clearly, more research is needed to assess how small variations in interletter spacing affect silent normal reading -using both global and local measures (e.g., using a moderate increase [around +1.5 ] in interletter spacing, as in "the great cuisine", the default settings would be "the great cuisine").

In sum, the present experiments have demonstrated that small variations of interletter spacing produce an impact on word identification times - presumably via an increase in the "quality of information". More research is needed to examine in greater detail the optimal interletter spacing values using a large set of spacing conditions both at the single-word identification level and at the sentence reading level. Importantly, these experiments should not just be conducted on a normal adult population, but also on other populations, such as beginning readers (see Woods et al. 2005) or individuals with visual impairment (McLeish 2007). In this light, the American Foundation for the Blind (2010) suggests that "spacing between letters should be wide", however, they offered no value of how wide interletter spacing should be. Clearly, more attention should be paid to systematically controlled studies on typographic factors in the psychological community.

\section{Acknowledgments}

The research reported in this article has been partially supported by Grants PSI2008-04069/PSIC from the Spanish Ministry of Education and Science to Manuel Perea and NSF SES-0446869 to Pablo Gomez. We thank two anonymous reviewers for helpful criticism of an earlier draft.

\section{References}

Acha, J., \& Perea, M. (2008a). The effects of length and transposed-letter similarity in lexical decision: Evidence with beginning intermediate, and adult readers. British Journal of Psychology, 99, 245-264.

Acha, J., \& Perea, M. (2008b). The effect of neighborhood frequency in reading: Evidence with transposed-letter neighbors. Cognition, 108, 290-300.

Andrews, S. (Ed.). (2006). From inkmarks to ideas: Current issues in lexical processing. Hove, UK: Psychology Press.

Blind, American Foundation for the (2010). Tips for Making Print More Readable. Retrieved on December 24, 2010 from. http://www.afb.org/Section.asp? SectionID $=26 \&$ TopicID $=144 \&$ DocumentID $=210$

Bouma, H. (1970). Interaction effects in parafoveal letter recognition. Nature, 226 177-178.

Bouma, H. (1973). Visual interference in the parafoveal recognition of initial and final letters of words. Vision Research, 13, 762-782.

Chung, S. T. L. (2002). The effect of letter spacing on reading speed in central and peripheral vision. Investigative Ophthalmology \&' Visual Science, 43, 1270-1276.

Chung, S. T. L., \& Legge, G. E. (2009). Precision of position signals for letters. Vision Research, 49, 1948-1960.

Chung, S. T. L., Levi, D. M., \& Legge, G. E. (2001). Spatial-frequency and contrast properties of crowding. Vision Research, 41, 1833-1850. 
Cohen, L., Dehaene, S., Vinckier, F., Jobert, A., \& Montavont, A. (2008). Reading normal and degraded words: Contribution of the dorsal and ventral visual pathways. Neurolmage, 40, 353-366.

Coltheart, M., Rastle, K., Perry, C., Langdon, R., \& Ziegler, J. (2001). DRC: A Dual Route Cascaded model of visual word recognition and reading aloud. Psychological Review, $108,204-256$.

Davis, C. J. (2010). The spatial coding model of visual word identification. Psychological Review, 117, 713-758.

Davis, C. J., \& Perea, M. (2005). BuscaPalabras: A program for deriving orthographic and phonological neighborhood statistics and other psycholinguistic indices in Spanish. Behavior Research Methods, 37, 665-671.

Davis, C. J., Perea, M., \& Acha, J. (2009). Re(de)fining the orthographic neighbourhood: The role of addition and deletion neighbours in lexical decision and reading. Journal of Experimental Psychology. Human Perception and Performance, 35, 1550-1570.

Eriksen, B. A., \& Eriksen, C. W. (1974). Effects of noise letters upon the identification of a target letter in a non-search task. Perception \& Psychophysics, 16, 143-149.

Forster, K. I., \& Forster, J. C. (2003). DMDX: A windows display program with millisecond accuracy. Behavior Research Methods, Instruments, \& Computers, 35, 116-124.

Gomez, P., Ratcliff, R., \& Perea, M. (2007). A model of the go/no-go task. Journal of Experimental Psychology: General, 136, 389-413.

Gomez, P., Ratcliff, R., \& Perea, M. (2008). The overlap model: A model of letter position coding. Psychological Review, 115, 577-601.

Grainger, J., \& Jacobs, A. M. (1996). Orthographic processing in visual word recognition: A multiple read-out model. Psychological Review, 103, 518-565.

Grainger,J., Granier, J. P., Farioli, F., Van Assche, E., \& van Heuven, W. (2006). Letter position information and printed word perception: The relative-position priming constraint. Journal of Experimental Psychology. Human Perception and Performance, 32, 865-884.

Huey, E. B. (1908). The psychology and pedagogy of reading. New York: McMillan. Republished in 1968. Cambridge: MA: MIT Press.

Johnson, R. L., Perea, M., \& Rayner, K. (2007). Transposed-letter effects in reading: Evidence from eye movements and parafoveal preview. Journal of Experimental Psychology: Human Perception and Performance, 33, 209-229.

Larson, K. (2006). The technology of text. Retrieved on December 24, 2010 from. http:// spectrum.ieee.org/computing/software/the-technology-of-text/0

Latham, K., \& Whitaker, D. (1996). A comparison of word recognition and reading performance in foveal and peripheral vision. Vision Research, 36, 2665-2674.

McLeish, E. (2007). A study of the effect of letter spacing on the reading speed of young readers with low vision. British Journal of Visual Impairment, 25, 133-143.

McClelland, J. L., \& Rumelhart, D. E. (1981). An interactive activation model of context effects in letter perception: Part 1. An account of Basic Findings. Psychological Review, 88, 375-407.

Moret-Tatay, C., \& Perea, M. (in press). Do serifs provide an advantage in the recognition of written words? Journal of Cognitive Psychology. DOI: 10.1080/09541446.2010.546781.

Norris, D., Kinoshita, S., \& van Casteren, M. (2010). A stimulus sampling theory of letter identity and order. Journal of Memory and Language, 62, 254-271.

O'Connor, R. E., \& Forster, K. I. (1981). Criterion bias and search sequence bias in word recognition. Memory \& Cognition, 9, 78-92.
Paterson, K. B., \& Jordan, T. R. (2010). Effects of increased letter spacing on word identification and eye guidance during reading. Memory \& Cognition, 38, 502-512. Perea, M., \& Acha, J. (2009). Space information is important for reading. Vision Research, 49, 1994-2000.

Perea, M., \& Pollatsek, A. (1998). The effects of neighborhood frequency in reading and lexical decision. Journal of Experimental Psychology. Human Perception and Performance, 24, 767-777.

Perea, M., \& Rosa, E. (2002). Does "whole word shape" play a role in visual word recognition? Perception \& Psychophysics, 64, 785-794.

Perea, M., Rosa, E., \& Gómez, C. (2005). The frequency effect for pseudowords in the lexical decision task. Perception \& Psychophysics, 67, 301-314.

Pollatsek, A., \& Well, A. D. (1995). On the use of counterbalanced designs in cognitive research: A suggestion for a better and more powerful analysis. Journal of Experimental Psychology. Learning, Memory, and Cognition, 21, 785-794.

Posner, M. I. (2005). Timing the brain: mental chronometry as a tool in neuroscience. PLoS Biology, 3, e51.

Prince, J. H. (1959). Special print for subnormal vision. American Journal of Ophthalmology, 48, 122-124.

Ratcliff, R., Gomez, P., \& McKoon, G. (2004). A diffusion model account of the lexical decision task. Psychological Review, 111, 159-182.

Rayner, K. (1998). Eye movements in reading and information processing. Psychological Bulletin, 124, 372-422.

Rayner, K., Fischer, M. H., \& Pollatsek, A. (1998). Unspaced text interferes with both word identification and eye movement control. Vision Research, 38, 1129-1144.

Rayner, K., Slattery, T. J., \& Bélanger, N. N. (2010). Eye movements, the perceptual span, and reading speed. Psychonomic Bulletin E Review, 17, 834-839.

Rumelhart, D. E., \& Siple, P. (1974). The process of recognizing tachistoscopically presented words. Psychological Review, 81, 99-118.

Slattery, T. J., \& Rayner, K. (2010). The influence of text legibility on eye movements during reading. Applied Cognitive Psychology, 24, 1129-1148.

Sternberg, S. (1969). Memory-scanning: Mental processes revealed by reaction-time experiments. American Scientist, 57, 421-457.

Tai, Y. Ch., Sheedy, J., \& Hayes, J. (2009). June). Forest Grove, OR: The effect of interletter spacing on reading. Paper presented at the Computer Displays \& Vision conference.

Tracy, W. (1987). Letters of credit: A view of type design. London: Godine.

Van Overschelde, J. P., \& Healy, A. F. (2005). A blank look in reading: The effect of blank space on the identification of letters and words during reading. Experimental Psychology, 52, 213-223.

Whitney, C. (2001). How the brain encodes the order of letters in a printed word: The SERIOL model and selective literature review. Psychonomic Bulletin \& Review, 8 , 221-243.

Woods, R. J., Davis, K., \& Scharff, L. F. V. (2005). Effects of typeface and font size on legibility for children. American Journal of Psychological Research, 1, 86-102.

Yu, D., Cheung, S. -H., Legge, G. E., \& Chung, S. T. L. (2007). Effect of letter spacing on visual span and reading speed. Journal of Vision, 7, 1-10.

Yu, D., Park, H., Gerold, D., \& Legge, G. E. (2010). Comparing reading speed for horizonta and vertical English text. Journal of Vision, 10, 1-17. 